\title{
Acoustic Immunosensing of Exosomes Using a Quartz Crystal Microbalance with Dissipation Monitoring
}

\author{
Jugal Suthar, Edward S. Parsons, Bart W. Hoogenboom, Gareth R. Williams, and Stefan Guldin* \\ Cite This: Anal. Chem. 2020, 92, 4082-4093 \\ Read Online
}

ABSTRACT: Exosomes are endocytic lipid-membrane bound bodies with the potential to be used as biomarkers in cancer and neurodegenerative disease. The limitations and scarcity of current exosome characterization approaches have led to a growing demand for translational techniques, capable of determining their molecular composition and physical properties in physiological fluids. Here, we investigate label-free immunosensing, using a quartz crystal microbalance with dissipation monitoring (QCM-D), to detect exosomes by exploiting their surface protein profile. Exosomes expressing the transmembrane protein CD63 were isolated by size-exclusion

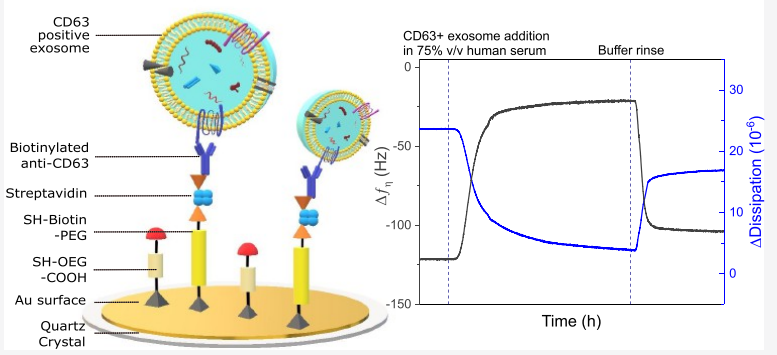
chromatography from cell culture media. QCM-D sensors functionalized with anti-CD63 antibodies formed a direct immunoassay toward CD63-positive exosomes in 75\% v/v serum, exhibiting a limit-of-detection of $2.9 \times 10^{8}$ and $1.4 \times 10^{8}$ exosome sized particles (ESPs)/mL for frequency and dissipation response, respectively, i.e., clinically relevant concentrations. Our proof-of-concept findings support the adoption of dual-mode acoustic analysis of exosomes, leveraging both frequency and dissipation monitoring for use in bioanalytical characterization.

\section{INTRODUCTION}

Extracellular vesicles (EVs) are heterogeneous, biomolecular structures enclosed by a lipid bilayer. They are secreted by nearly all eurkaryotic cells into the extracellular space and most bodily fluids. ${ }^{1}$ Of particular interest are exosomes, a subset of EVs with a nanoscale size range $(30-150 \mathrm{~nm})$ originating from invaginations of early endosomes and released upon the fusion of multivesicular bodies with the cell membrane. ${ }^{2}$ They are enriched in nucleic acids, surface proteins such as tetraspannins (CD63, CD81, and CD9), and cytosolic proteins including heat shock proteins (HSP90 and HSP70) and TSG101.,4

Traditionally thought to function as cellular waste bins, the roles of exosomes in intercellular communication, ${ }^{5}$ disease propagation, and regenerative processes are now well established. 6 Crucially, exosome concentrations and phenotype have been shown to vary between healthy and diseased states, reflecting their parental cell of origin. ${ }^{8,9}$ Thus, exosomes have attracted widespread interest as a concentrated source of biomarkers for minimally invasive, point-of-care liquid biopsies. $^{10,11}$

Typically, exosomes are characterized via nanoparticle tracking analysis (NTA). Here, the imaging of light scattered from particles moving under Brownian diffusion is used to determine the hydrodynamic size and concentration. ${ }^{12}$ Alternatively, tunable elastomeric pore sensing analyzes individual particles via the electrical impedance they impart at an aperture. ${ }^{13}$ These methods are often coupled with total protein quantification via colorimetric assays such as microBCA and Bradford. ${ }^{14}$ One limitation of the above techniques is that they do not selectively distinguish between exosomes and other EVs, protein aggregates, and lipoproteins. This lack of discrimination is compounded by the choice of exosome isolation technique, where commonly adopted centrifugation and polymer precipitation methods coisolate nonexosomal artifacts from complex media. ${ }^{15}$ Thus, there is a difficulty in defining subsets within a heterogeneous exosome population, which hinders these techniques in sensing specific markers in complex biological matrices. ${ }^{16}$

By contrast, flow cytometry ${ }^{17,18}$ and fluorescence-based NTA have been successfully employed to quantify exosomes and determine their phenotypes via selective tagging of their surface epitopes. ${ }^{19}$ Nonetheless, labeling approaches are restricted by the strength of interaction between the label and exosome. Furthermore, these techniques are largely destructive, limiting downstream application of the analyte. Enzyme-linked immunosorbent assay (ELISA) is the current gold standard for exosomal protein quantification, with sensitivity in the picomolar range. ${ }^{20}$ However, traditional ELISAs can suffer from a lack of multiplexing, crosscontamination, and limited potential for point-of-care application. Recently, Ren et al. introduced an enzyme-free colorimetric immunoassay toward alpha-fetoprotein (AFP),

Received: December 19, 2019

Accepted: January 30, 2020

Published: January 30, 2020 
using an antibody-labeled metal-polydopamine framework that displayed sensitivity down to $2.3 \mathrm{pg} \mathrm{mL}^{-1}$. $^{21}$ An alternative approach with similar sensitivity $\left(5.3 \mathrm{pg} \mathrm{mL}^{-1}\right)$ was devised by the same group via near-infrared excitation of nanospheres as part of a photoelectrochemical enzyme immunoassay for AFP detection. $^{22}$

There is increasing interest in automation and miniaturization of exosome screening through microfluidics and lab-ona-chip approaches to match the clinical demand of minimally invasive patient stratification. ${ }^{23,24}$ Examples of advanced exosomal analytical approaches include interferometry, ${ }^{25}$ electrochemistry, ${ }^{26,27}$ and optical sensors utilizing nanoplasmonics. $^{28,29}$ Recently, Rupert et al. successfully demonstrated surface plasmon resonance (SPR) based sensing of CD63-positive exosomes through surface based immunocapture. ${ }^{30}$ Collectively, the above-mentioned techniques provide a sensitive, label-free, and real-time assessment of exosomes. A potential drawback of these methods is the difficulty in distinguishing between exosome and artifactual binding phenomena. ${ }^{31,32}$ Qiu et al. was able to overcome background fluctuations and interference in a photoelectrochemical biosensor by using a ratiometric aptasensor, which spatially resolved dual signal readouts from two working electrodes. ${ }^{33}$ Recently, $\mathrm{Yu}$ et al. successfully employed a carbon-nanotube modified pressure electrode to discern between human serum biomarkers and the analyte of interest, carcinoembryonic antigen. ${ }^{34}$ This is an essential consideration, as not all circulating particles may be exosomal in composition, potentially leading to a false positive result if not appropriately distinguished from other colloidal contaminants.

To overcome the issue of specificity, this study employs quartz crystal microbalance with dissipation (QCM-D) monitoring, to leverage differences in mechanical properties between exosomes and associated contaminants in colloidal suspension. QCM-D is capable of characterizing interfacial structure, binding kinetics, molecular affinity, and mechanical properties of the adsorbent. ${ }^{35}$ Advantages of the acoustic technique include label-free, real-time measurements ${ }^{36}$ and ease of miniaturization. ${ }^{37}$ For a $5-\mathrm{MHz}$ resonator in water, the acoustic wave possesses a penetration depth of around $250 \mathrm{~nm}$ from the oscillator surface, which matches the size of the exosomes. ${ }^{38}$ Nonetheless, QCM-D has yet to be fully exploited for exosome characterization. QCM-D transduced immunosensing has been explored to build assays where an antibody serves as a bioreceptor toward a target analyte. For instance, Uludag and Tothill demonstrated its applicability for the detection of a prostate specific antigen. ${ }^{39}$ Pirincci et al. evaluated a competitive immunoassay for the detection of mycotoxin Ochratoxin A. ${ }^{40}$ Tang et al. devised an immunoassay, which exploits the frequency change upon glucose displacement of bound concanavalin-A complex to detect brevetoxin down to $0.6 \mathrm{pg} \mathrm{mL}^{-1}$.

In this work, we establish a direct immunoassay of CD63positive exosomes using QCM-D. After successfully isolating and characterizing exosomes, we identify an optimal antibody immobilization approach. The sensor performance is then validated by assessing its sensitivity toward spiked samples of CD63 protein. We first evaluate the platform performance toward purified CD63 exosomes in buffer, as isolated by sizeexclusion chromatography. We then determine the specificity, limit-of-detection (LOD), and limit-of-quantification (LOQ) of the approach, toward CD63 exosomes spiked in human serum, by comparing the target platform performance to a control surface. Our findings are validated by complementary in-liquid atomic force microscopy (AFM).

\section{EXPERIMENTAL SECTION}

Exosome Isolation and Characterization. Size-Exclusion Chromatography. Size-exclusion chromatography (SEC) was chosen as the isolation technique for exosomes from human umbilical cord mesenchymal stem cell culture media (HUMSCCM), based on previous work in the field. ${ }^{42}$ HUMSSCM was first filtered with a $0.45 \mu \mathrm{m}$ filter (Merck Millipore, USA). Thirty milliliters of clarified media was subsequently concentrated using Amicon Ultra-15 centrifugal filters with a $10 \mathrm{kDa}$ pore size cutoff (Merck Millipore, USA). The filters were spun at $4000 \mathrm{~g}$ for $30 \mathrm{~min}$ at $4{ }^{\circ} \mathrm{C}$. Postspin, 0.5 $\mathrm{mL}$ of concentrated filtrate was loaded onto a $\mathrm{qEV}$ SEC column (Izon Science, UK). Next, $0.2 \mu \mathrm{M}$ filtered HEPES buffered saline (HBS, 0.01 M HEPES, pH 7.4, $0.15 \mathrm{M} \mathrm{NaCl}$; GE Healthcare Life Sciences, Sweden) was used as the eluting buffer at a flow rate of $1 \mathrm{~mL} / \mathrm{min}$. Twenty $1 \mathrm{~mL}$ fractions were collected and stored at $-80{ }^{\circ} \mathrm{C}$.

NTA Analysis of SEC Fractions. The concentration and hydrodynamic size of particulates for each fraction were assessed by nanoparticle tracking analysis (NTA) with the Nanosight LM10 instrument (Malvern Instruments, UK). The machine was calibrated with $100 \mathrm{~nm}$ polystyrene beads (Thermofisher Scientific, UK) prior to fraction assessment. Measurement specifications were as follows: $532 \mathrm{~nm}$ green laser, five videos per fraction, $60 \mathrm{~s}$ video length, shutter speed of 25-32 ms, camera gain of 400, camera level 15 , lower threshold of 910, and higher threshold of 11180 . Captured videos were processed with the NTA software (version 3.2), a detection threshold of 5 , auto settings for blur, minimum track length, and minimum particle size. Measurements were carried out in static mode at room temperature.

Protein Content Analysis. Total protein concentrations of SEC fractions were determined using the Pierce Micro Bicinchoninic Acid (Micro BCA) protein assay kit (ThermoFisher, UK) per the manufacturer's instructions (see Supporting Information for details).

Western Blot Analysis of Final Isolate. To validate the SEC isolation, exosome presence was verified through Western blot analysis via capillary gel electrophoresis format, using a WES instrument from Protein Simple (Biotechne Ltd., USA). SEC fraction 4 was selected for analysis as it possessed the highest ESP purity of $1.6 \times 10^{10} \mathrm{ESPs} / \mu \mathrm{g}$ of protein (Figure S1). Exosomal proteins Alix $(97 \mathrm{kDa})$ and tetraspannin CD63 (57 $\mathrm{kDa}$ ) were probed by chemiluminescent immunoassay, using mouse monoclonal anti-Alix (634502, Biolegend UK) and mouse monoclonal anti-CD63 (353013, Biolegend UK) as primary antibodies. The WES run was conducted per the manufacturer's instruction (see Supporting Information for details).

Gold Immuno-Electron Microscopy. Microscopy images were captured on a Jeol 2100 TEM instrument (Japan). SEC fraction 4 was diluted 100 -fold, and $20 \mu \mathrm{L}$ was spotted onto parafilm. A Formvar/carbon coated copper grid (200 mesh) was incubated on top of the sample for $7 \mathrm{~min}$. The grid was washed three times with filtered phosphate buffered saline (PBS) buffer ( $\mathrm{pH} 7.4,137 \mathrm{mM} \mathrm{NaCl}, 2.7 \mathrm{mM} \mathrm{KCl}, 10 \mathrm{mM}$ $\mathrm{Na}_{2} \mathrm{HPO}_{4}, 1.8 \mathrm{mM} \mathrm{KH} \mathrm{PO}_{4}$; Sigma-Aldrich, USA). The grid was then incubated with $20 \mu \mathrm{L}$ of normal serum block (927501, Biolegend UK), matching the species in which the secondary antibody was generated, for $30 \mathrm{~min}$. Grids were 
subsequently washed three times with PBS. Twenty microliters of a 1:20 mouse monoclonal anti-CD63 solution (353013, Biolegend UK) in PBS/5\% normal serum block was incubated with the grids for $1 \mathrm{~h}$. The grid was washed six times with PBS. Thereafter, the grids were incubated with goat antimouse IgG conjugated gold nanoparticles (Insight Biotechnology, UK), at a 1:20 dilution in PBS/5\% normal serum block, for $1 \mathrm{~h}$ in the dark. The grids were washed six times with PBS and incubated with $20 \mu \mathrm{L}$ of $1 \%$ uranyl acetate negative stain, mixed with $2 \%$ phosphotungstic acid in a 1:10 ratio in DI water, for $5 \mathrm{~min}$. Excess dye was removed with filter paper held at $45^{\circ}$, and grids were then left to dry before analysis.

QCM-D Measurements. All QCM-D measurements were carried out using a Q-Sense E4 instrument (Biolin Scientific, Sweden). Analysis of frequency and dissipation response was conducted with the QTools software, version 3.0.17.560 (Biolin Scientific, Sweden). Changes in resonance frequency $(\Delta f)$ were recorded from the third, fifth, seventh, ninth, and 11th overtones. The presented data relates to the fifth overtone, with variation of $(\Delta f)$ between overtones being $10 \%$ or less. In all instances, samples were degassed prior to exchange in the QCM flow module, and AT-cut, 5-MHz gold coated quartz crystal sensors with a $0.79 \mathrm{~cm}^{2}$ active area (Biolin, Sweden) were used.

An optimal antibody immobilization procedure was first investigated, comparing a covalent- and affinity-based approach. The covalent approach involved the formation of a self-assembled monolayer (SAM). A $1 \mathrm{mM}$ ethanolic solution of SH-PEG(2 kDa)-COOH and $\mathrm{SH}-\mathrm{PEG}(800 \mathrm{Da})-\mathrm{CH}_{3}$ (Laysan Bio, USA) in a 1:3 mixture was flowed across the sensor surface at $7.5 \mu \mathrm{L} / \mathrm{min}$ overnight. The molarity was used as per previous SAM optimization studies. ${ }^{43}$ Carboxylic acid end groups were activated with an equal parts solution of 1ethyl-3-(3-(dimethylamino)propyl)carbodiimide (EDC) crosslinker $(0.4 \mathrm{M})$ and $\mathrm{N}$-hydroxysuccinimide (NHS; $0.1 \mathrm{M})$ in $\mathrm{pH}$ 5.5 2-(N-morpholino)ethanaesulfonic acid (MES) coupling buffer $(50 \mathrm{mM})$ at $7.5 \mu \mathrm{L}$ per minute. Twenty micrograms per milliliter of mouse monoclonal anti-CD63 (353013, Biolegend UK) was immobilized on the surface by binding the amine group of the antibody to the activated carboxylic acid group on the functionalized sensor. This was conducted at $10 \mu \mathrm{L} / \mathrm{min}$, in $\mathrm{pH} 7.4 \mathrm{HBS}$ buffer. Unbound active groups were deactivated with $1 \mathrm{M}$ ethanolamine for 20 min at $40 \mu \mathrm{L} / \mathrm{min}$. This preceded a rinse step and response stabilization for $30 \mathrm{~min}$ prior to sample addition.

The affinity-based approach utilized an alternative SAM. Here, a $1 \mathrm{mM}$ ethanolic solution of SH-PEG(2 $\mathrm{kDa})$-Biotin (Laysan Bio, USA) and spacer molecule SH-OEG(800 Da)$\mathrm{COOH}$ (Polypure, Norway) at a 1:9 ratio was flowed across the sensor surface at $7.5 \mu \mathrm{L} / \mathrm{min}$ overnight. The molar ratio was based on optimized protocols in previous sensing studies. $^{44,45}$ A $100 \mu \mathrm{g} / \mathrm{mL}$ solution of streptavidin (SAv; Sigma-Aldrich, USA) was flowed across the sensor surface at $10 \mu \mathrm{L} / \mathrm{min}$, followed by a rinse step of HBS at $80 \mu \mathrm{L} / \mathrm{min}$. Twenty micrograms per milliliter of mouse monoclonal biotinylated-anti-CD63 (353017, Biolegend UK) was immobilized on the surface at $10 \mu \mathrm{L} / \mathrm{min}$, followed by another rinse step and response stabilization for $30 \mathrm{~min}$ prior to sample addition.

The affinity-based approach was chosen as the method of choice for the following investigations. Immuno-sensor functionality toward spiked CD63 and exosomal CD63 was assessed. Spiked samples of CD63 (Sinobiological, China) of concentrations $1.25,2.5,5,10,20,40,80,160$, and $320 \mathrm{nM}$ determined the platform's sensitivity toward the target antigen in HBS buffer. Performance toward exosomal CD63 was initially assessed by measuring responses to SEC fractions 3, 4, 5 , 6, and 7, following a 100-factor dilution in HBS buffer. Sensitivity toward CD63-positive exosomes in HBS buffer was tested using dilutions of fraction 4 from SEC isolations with concentrations being verified by NTA. The following concentrations were assessed: $1 \times 10^{8}, 2.5 \times 10^{8}, 5 \times 10^{8}$, $7.5 \times 10^{8}, 1 \times 10^{9}, 5 \times 10^{9}, 1 \times 10^{10}$, and $5 \times 10^{10} \mathrm{ESPs} / \mathrm{mL}$. The same concentrations of ESPs were spiked into $75 \% \mathrm{v} / \mathrm{v}$ serum (Sigma-Aldrich, USA) to determine platform sensitivity toward CD63-positive exosomes in more complex media. Determination of specificity and signal-to-noise ratio (SNR) required response comparison with a control sensor surface. Here, biotin-IgG isotype control antibody (400103, Biolegend UK) was used instead of biotin-anti-CD63. Binding response was compared to a target sensor against a $5 \times 10^{9} \mathrm{ESPs} / \mathrm{mL}$ sample in HBS buffer and $1 \times 10^{9} \mathrm{ESPs} / \mathrm{mL}$, spiked in $0 \%$, $25 \%, 50 \%$, and $75 \% \mathrm{v} / \mathrm{v}$ serum. For the purpose of this work, LOD and LOQ were defined as the concentration eliciting an SNR of 3 and 10, respectively, as governed by best practice. ${ }^{46}$ SNR was calculated by a ratio of the response seen on the target sensor and that on a control sensor surface.

To ensure reproducibility of the fabrication process, all analytes were prepared using the same degassed HBS stock solution or serum stock to minimize impact of buffer properties during sample exchange in observed responses. These were prepared to identical volumes $(0.25 \mathrm{~mL}$ per sensor). All reagents were sourced from the same suppliers throughout the study to avoid influences of differing characteristics or quality. In all cases, the analyte was flowed at $10 \mu \mathrm{L} / \mathrm{min}$, and a sensor was reserved for baseline measurement, to account for drift and background changes induced by buffer exchange. Frequency and dissipation responses are reported net or post-HBS rinse, to account for the removal of weakly bound analytes.

AFM Measurements. AFM was carried out on ultraflat gold substrates (Platypus Tech, USA) with a Multimode 8 instrument (Bruker, Santa Barbara, USA), using imaging based on fast force spectroscopy (PeakForce Nanomechanical mapping), with $1 \mathrm{kHz}$ oscillation frequency and $5 \mathrm{~nm}$ amplitude. Imaging was conducted in solution with a PFHR-B probe (Bruker, spring constant $=0.12 \mathrm{~N} / \mathrm{m}$, resonance frequency $=100 \mathrm{kHz}$ in air). Filtered HBS served as imaging buffer. Substrates were incubated overnight in the SAM solution at room temperature. Surfaces were functionalized with identical streptavidin and antibody solutions as used in the affinity approach, by introducing and washing directly within the liquid cell. For assessment of ESPs in buffer and serum, $100 \mu \mathrm{L}$ of $5 \times 10^{9} \mathrm{ESPs} / \mathrm{mL}$ in HBS buffer and $1 \times 10^{9}$ $\mathrm{ESPs} / \mathrm{mL}$ in $75 \% \mathrm{v} / \mathrm{v}$ serum were introduced into the chamber, respectively, followed by incubation for $30 \mathrm{~min}$, prior to washing with $1 \mathrm{~mL}$ of HBS buffer and image capture.

Images were processed with the Gwyddion software (version 2.5) by first aligning rows using a median of differences correction. Images were then flattened using mean plane subtraction. A three-pixel ( $\sim 6 \mathrm{~nm})$ Gaussian filter was applied to reduce image noise. Height and diameter profiles of particles were taken as an average from 15 detected particles across three micrographs. 


\section{A}

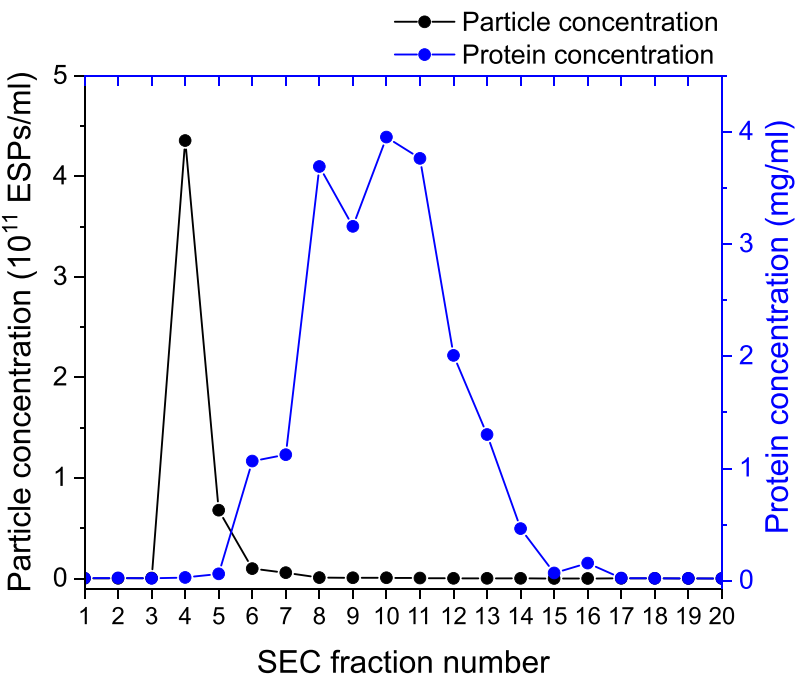

$\mathrm{B}$

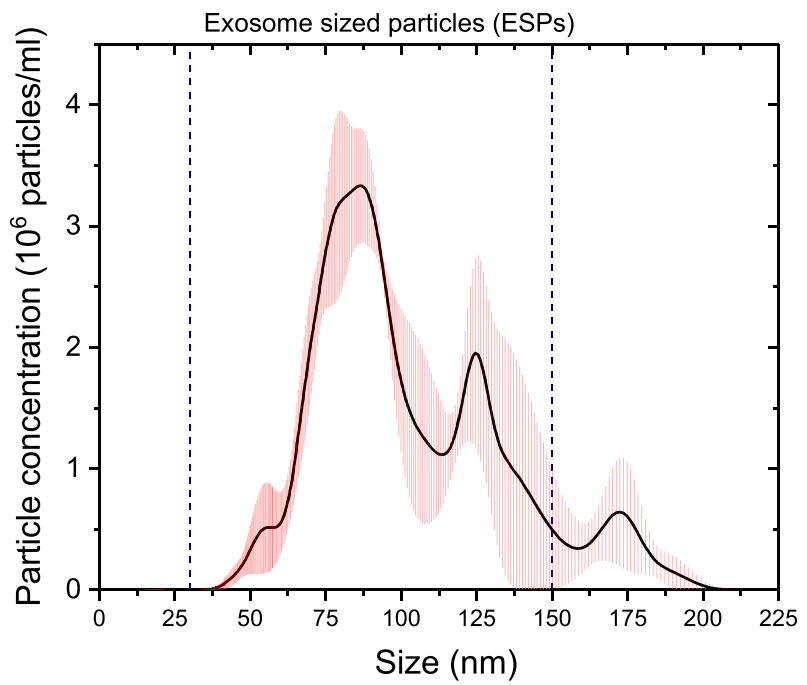

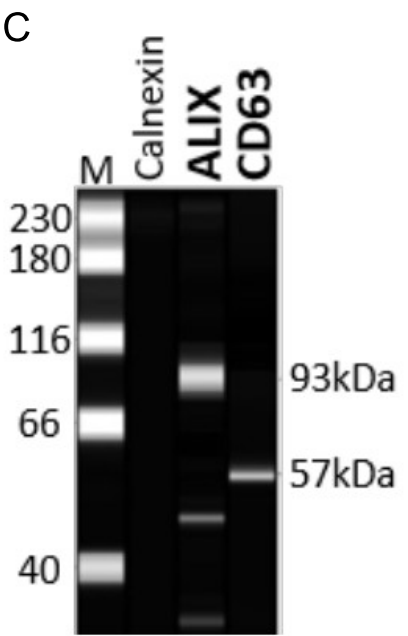
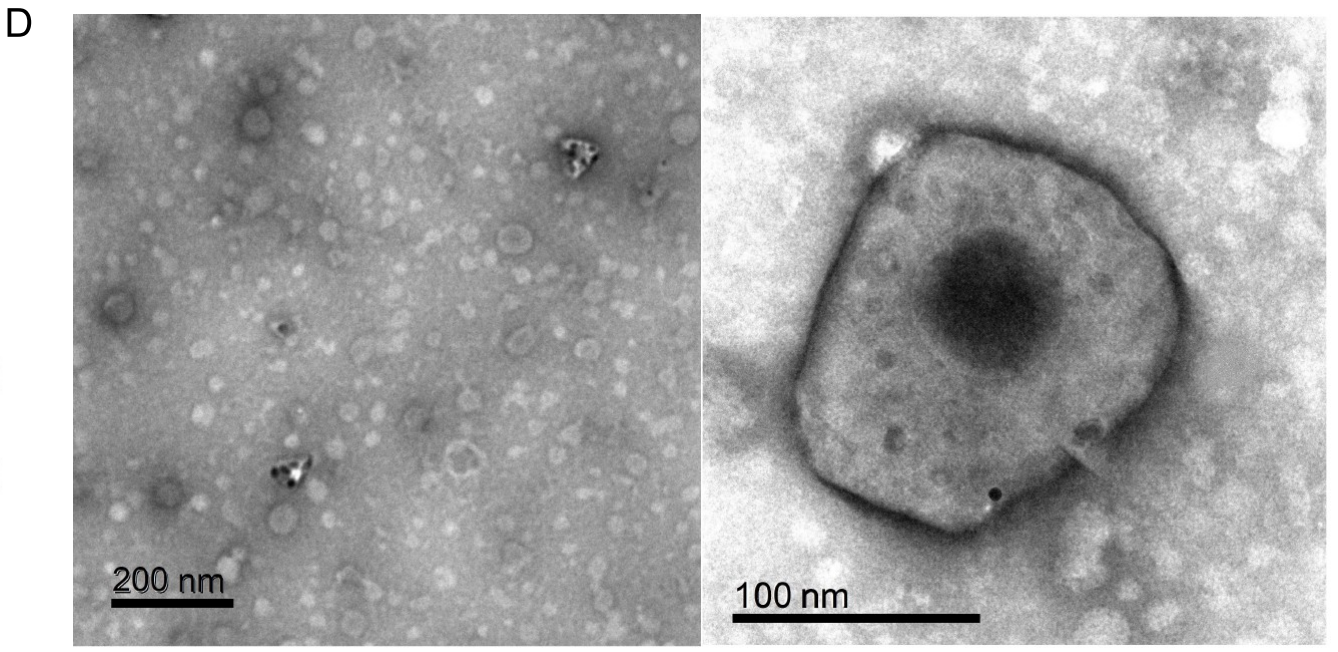

Figure 1. Exosome characterization obtained by SEC. (A) ESP and protein concentration profiles across SEC fractions using NTA and microBCA analysis. (B) Particle size distribution of SEC fraction 4. (C) Western blot identification of exosome enriched proteins, Alix and CD63, from fraction 4 and (D) Gold immuno-EM analysis confirming presence of CD63 protein at the exosome membrane.

\section{RESULTS AND DISCUSSION}

SEC Isolation of CD63-Positive Exosomes. The need for advanced analytical techniques is predicated on reproducible and efficient isolation from complex biological matrices. Moreover, the resulting exosomal samples must possess a high degree of structural and biological integrity. Thus, SEC was chosen as the isolation technique for its low impact on the nanosized vesicles. ${ }^{47}$

NTA analysis identified the fourth out of 20 collected fractions to have the highest yield of ESPs, with $4.4 \times 10^{11}$ ESPs $/ \mathrm{mL}$. The ESP number reduced sequentially in the following fractions, which coincided with an increase in total protein (Figure 1A). The elevated protein concentrations post fraction 6 are attributed to the increasing elution of nonexosomal, colloidal protein present in the starting cell culture media concentrate. The concentration of nonexosomal protein in latter fractions is significantly superior to the total protein quantified from high ESP yield fractions (4 and 5), supporting previous reports on SEC-based exosome isolation. ${ }^{42,48}$ Overall, these results suggest that SEC successfully isolated the large majority of ESPs from contaminating protein in the HUMSCCM source material, based on molecule size.
Size distribution analysis of fraction 4 confirmed that over $90 \%$ of the particles were within the ESP size range (Figure 1B). The isolation protocol was validated by Western blot, which identified exosome-enriched proteins, Alix and CD63, consistent with the presence of exosomes in the final sample. As evidenced by immuno-electron microscopy (immuno-EM) analysis (Figure 1C,D), the CD63 protein was shown to be accessible and present at the membrane surface. These results underpin the validity of surface-based immuno-capture of CD63-positive exosomes, as exploited herein.

Immuno-Sensor Performance toward Spiked-CD63. Prior to sensing exosomes, an appropriate antibody immobilization procedure was investigated. A covalent approach utilizing amine-coupling to directly bind anti-CD63 antibodies was compared with an affinity driven approach. Aminecoupling relies on the activation of carboxyl end groups on a SH-PEG-COOH:SH-PEG- $\mathrm{CH}_{3}$ mixed monolayer (formed by chemisorption) using carbodiimide chemistry to cross-link the amine residues found in lysine groups present in the antibody structure. ${ }^{49}$ The latter approach exploits the binding between SAv and biotin; the strongest naturally occurring noncovalent association $\left(K_{\mathrm{d}}=10^{-14} \mathrm{M}^{-1}\right) .^{50}$ SAv's four binding sites are 

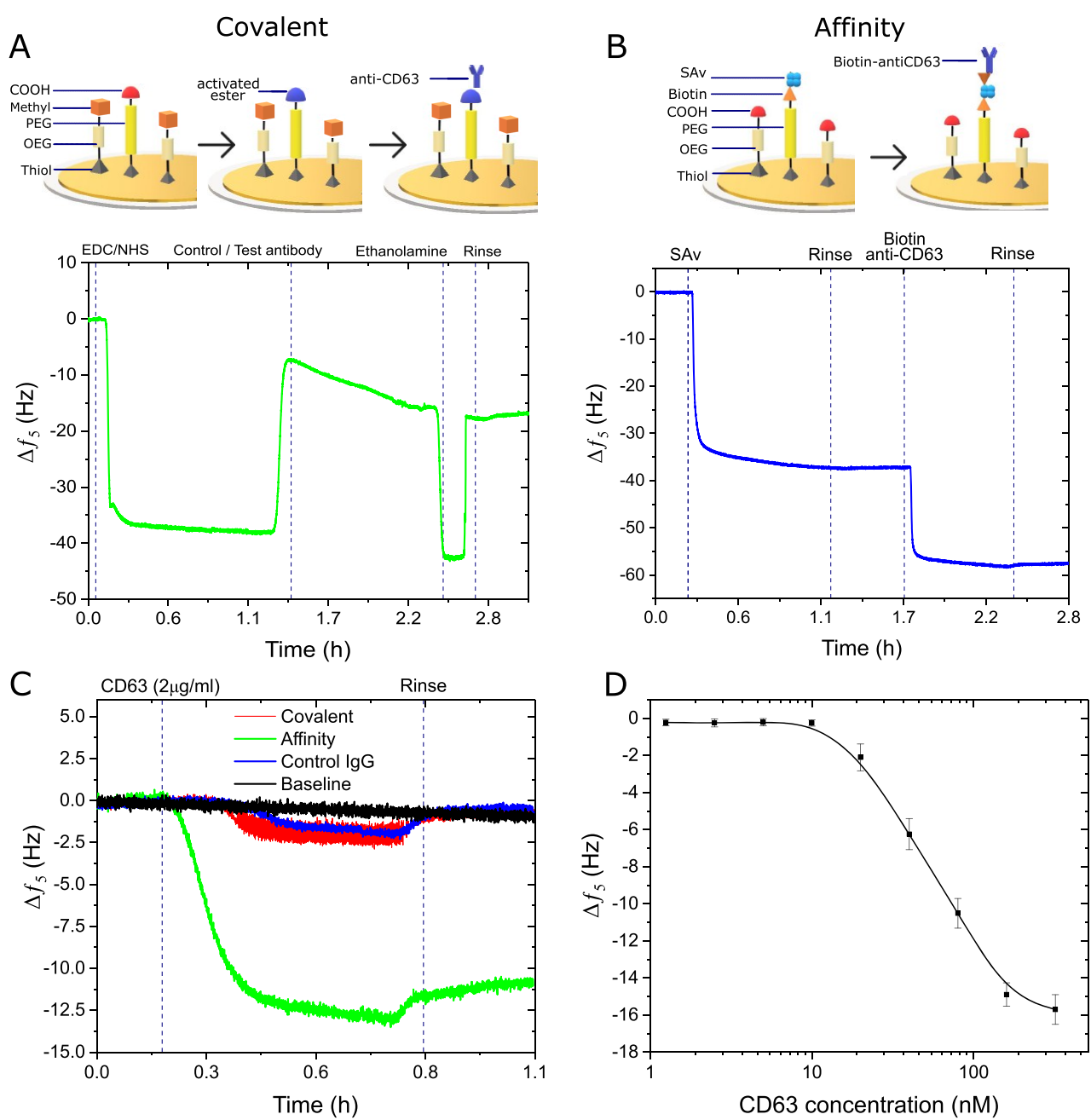

Figure 2. Example frequency profiles (post-SAM formation) for (A) covalent- and (B) affinity-based methods of antibody immobilization with diagrammatic illustration of surface modification. (C) Comparative frequency responses to $2 \mu \mathrm{g} / \mathrm{mL}$ of CD63 between antibody immobilization approaches. (D) Response curve for spiked-CD63 in buffer using optimized affinity functionalization method.

used to bind to biotin end groups on an SH-PEG-Biotin:SHOEG-COOH mixed monolayer and biotin-functionalized antiCD63 antibodies. ${ }^{51}$

The frequency response during the layer formation of the respective approaches is shown in Figure 2A,B. Net decreases in frequency are seen upon the addition of anti-CD63, SAv, and biotin-anti-CD63, with no indication of desorption (frequency increase) during the rinse step. Corresponding dissipation response to exosome-free CD63 proteins is shown in Table 1. Collectively, this suggests that the detection system has been successfully fabricated to the sensor surface.

A significant net reduction in frequency of the sensor oscillation was seen for the affinity approach in response to the CD63 sample (Figure 2C). This frequency response is a result of CD63 capture by surface bound anitbodies, effectively

Table 1. QCM-D Frequency and Dissipation Responses in Figure 2C

\begin{tabular}{llcrc} 
sensor & \multicolumn{1}{c}{ analyte } & conc & \multicolumn{1}{c}{$\Delta f(\mathrm{~Hz})$} & $\Delta D\left(1 \times 10^{-6}\right)$ \\
baseline & running buffer & & $0.61 \pm 0.13$ & $0.16 \pm 0.05$ \\
control & CD63 & $2 \mu \mathrm{g} / \mathrm{mL}$ & $-0.52 \pm 0.11$ & $0.15 \pm 0.05$ \\
covalent & CD63 & $2 \mu \mathrm{g} / \mathrm{mL}$ & $-0.82 \pm 0.17$ & $0.17 \pm 0.04$ \\
affinity & CD63 & $2 \mu \mathrm{g} / \mathrm{mL}$ & $-11.04 \pm 1.21$ & $0.73 \pm 0.12$
\end{tabular}

increasing the crystal thickness and modifying the crystal resonance during thickness-shear oscillation. With the ratio of dissipation and frequency change being $<4 \times 10^{-7} \mathrm{~Hz}^{-1}$, we can confirm the CD63 adsorbate layer is rigid in nature. ${ }^{52}$ This was contrasted by a negligible response for the covalently functionalized sensor, which represented only a marginally larger net frequency shift than found for the control surface (functionalized with nonspecific antibodies). Both of these responses are only marginally different from frequency drift witnessed with the running buffer alone, suggesting almost no CD63 capture to the sensor surface (Table 1).

Despite exhibiting clear antibody fabrication, the poor performance of the covalent approach may be caused by suboptimal antibody orientation. As previously reported, the amine coupling approach has the risk of random antibody orientation toward the sensor surface, as opposed to oriented covalent and noncovalent approaches. Steric hindrance can prevent optimal binding site exposure for antigen access. ${ }^{53-55}$ Conversely, the binding observed with the affinity approach was likely due to superior orientation of the antibody via the Fc-bound biotin. This is in line with previous studies, which reported benefits of improved antibody orientation, higher binding site availability, and improved antigen sensitivity by utilizing the SAv-biotin interaction for antibody immobiliza- 

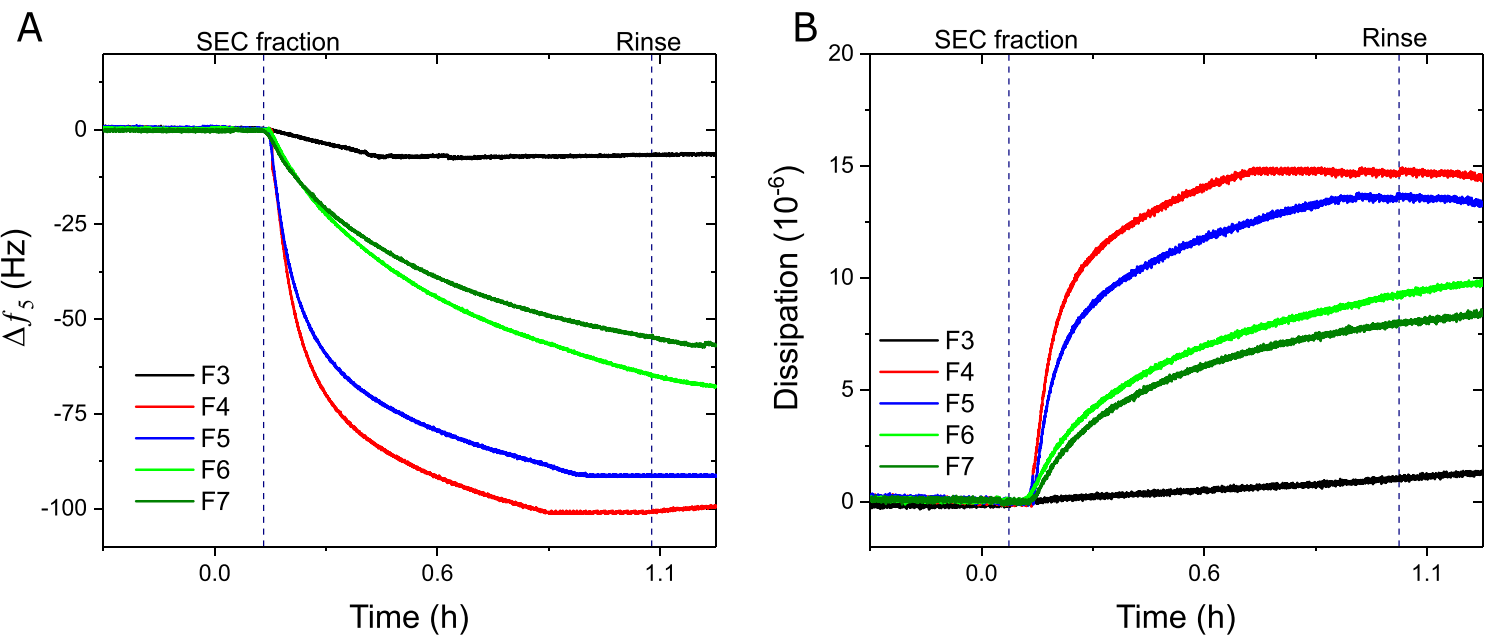

Figure 3. Example QCM-D profile responses to eluted SEC fractions taken from three independent runs. (A) Frequency response to SEC fractions 3-7 and (B) corresponding dissipation profiles.

tion as compared to randomly orientated covalent alternatives. $^{56,57}$

Having identified the affinity immobilization approach as offering optimal performance, this method was employed for the rest of the study. Figure S2 demonstrates the in situ overnight formation of a SAM at the sensor surface. The performance of the immuno-sensor was subsequently assessed toward exosome-free, spiked CD63 samples in HBS buffer (Figure 2D). Our platform displayed a LOD of $3.0 \mathrm{nM}$ and LOQ of $7.9 \mathrm{nM}$, with a dynamic range of 7.9-160 nM. This demonstrated the high sensitivity of the immuno-sensor toward the target antigen, aligning with sensitivities reported by other practitioners of acoustic biosensing. ${ }^{58,59}$

Sensitivity and Specificity Assessment toward CD63Positive Exosomes. For initial screening of CD63-positive exosomes, the various SEC fractions were compared for their acoustic response (Figure 3). QCM-D responses align well with the relative $\mathrm{ESP} / \mathrm{mL}$ concentrations as identified by NTA (Figure 1A), with higher frequency reductions for those fractions possessing larger ESP concentrations. ESP-rich fractions 4 and 5 exhibited significant responses $(\sim-100 \pm$ 8 and $\sim 91 \pm 7 \mathrm{~Hz}$, respectively) compared to fractions 3,6 , and 7. These responses are larger than found for fractions 6 and 7, in spite of higher total protein content in these fractions (Figure 1A). The greater responses may be due to (1) the larger size of the adsorbed material causing more liquid at the surface to be moved, (2) a high degree of hydrodynamic cosolvation, and/or (3) the greater mass of the fluid-filled vesicles.

An important component of acoustic exosome analysis is dissipation. As exosomes are not inherently rigid and prone to deformation, ${ }^{30}$ one expects significant friction in the newly formed adlayer during oscillation of the sensor, leading to regions of energy loss. Fractions 4 and 5 exhibited the most pronounced dissipation of $14.7 \pm 1.9$ and $13.5 \pm 1.6$, on average, respectively (Figure $3 \mathrm{~B}$ ). This phenomenon has been previously reported by groups sensing synthetic vesicles, ${ }^{60,61}$ where the viscoelastic structures resulted in energy storage (elastic) and loss (viscous) during oscillation. This is of interest, as it provides another discriminating factor to determine whether bound adsorbates are exosomal (vesicular and dissipative) or artifacts (nonvesicular and rigid). Hence, minimal responses seen for fractions 6 and 7 are likely a combination of smaller-sized vesicles expressing CD63, lower ESP concentrations overall, and the relative rigidity of the abundant nonexosomal protein. Notably, despite the ESP concentration in fraction 4 being 6.3-fold higher than fraction 5 (Figure 1A), the differences in frequency and dissipation response are in relative terms smaller and not proportional. This supports the response curve in Figure S4, as the concentrations of fractions 4 and $5\left(4.4 \times 10^{11}\right.$ and $6.7 \times$ $10^{10}$ per $\mathrm{ml}$, respectively) sit outside the dynamic range of the QCM platform, with the immunosensor nearing performance saturation at these concentrations.

Having demonstrated successful immuno-sensing of spikedCD63 and CD63-positive exosomes, we established the specificity of our sensing platform toward SEC purified ESPs in HBS buffer (see Figure S4). Critically, specificity in more complex biological media was also observed. Figure 4A-D compares the QCM-D response of a target and control surface, toward $1 \times 10^{9} \mathrm{ESPs} / \mathrm{mL}$, spiked in increasing concentrations of human serum. Note that the lags in response from ESP addition and rinse procedures are attributed to varying tube lengths to the respective sample chambers.

The maximum shift in frequency and dissipation increases along with serum content, likely due to a greater quantity of serum particles available to adsorb at the sensor surface. However, the net changes (postrinse) on both measurements for serum containing samples are similar to ESPs in $0 \% \mathrm{v} / \mathrm{v}$ serum, suggesting a large proportion of the prerinse shift was caused by loosely bound, nonspecific adsorbates, of which the majority is removed upon buffer addition. No significant differences were found in net frequency and dissipation changes between ESPs in buffer alone versus ESPs in serum samples for the $95 \%$ confidence interval, using a Student $t$-test (two-tailed). These results indicate that the presence of complex colloidal contaminants does not hinder the target surface's ability to sense CD63-positive exosomes. The control surfaces did reveal some signatures of binding, but this response was nearly overcome upon rinsing with buffer. Therefore, it is likely this binding was weak in nature. In $75 \%$ $\mathrm{v} / \mathrm{v}$ serum, an average SNR of 5.8 and 11.4 was demonstrated by the frequency and dissipation modes of measurement, respectively (with exosomes in the picomolar concentration range). Interestingly, our findings highlight dissipation as a more sensitive and selective measurement over frequency. In 

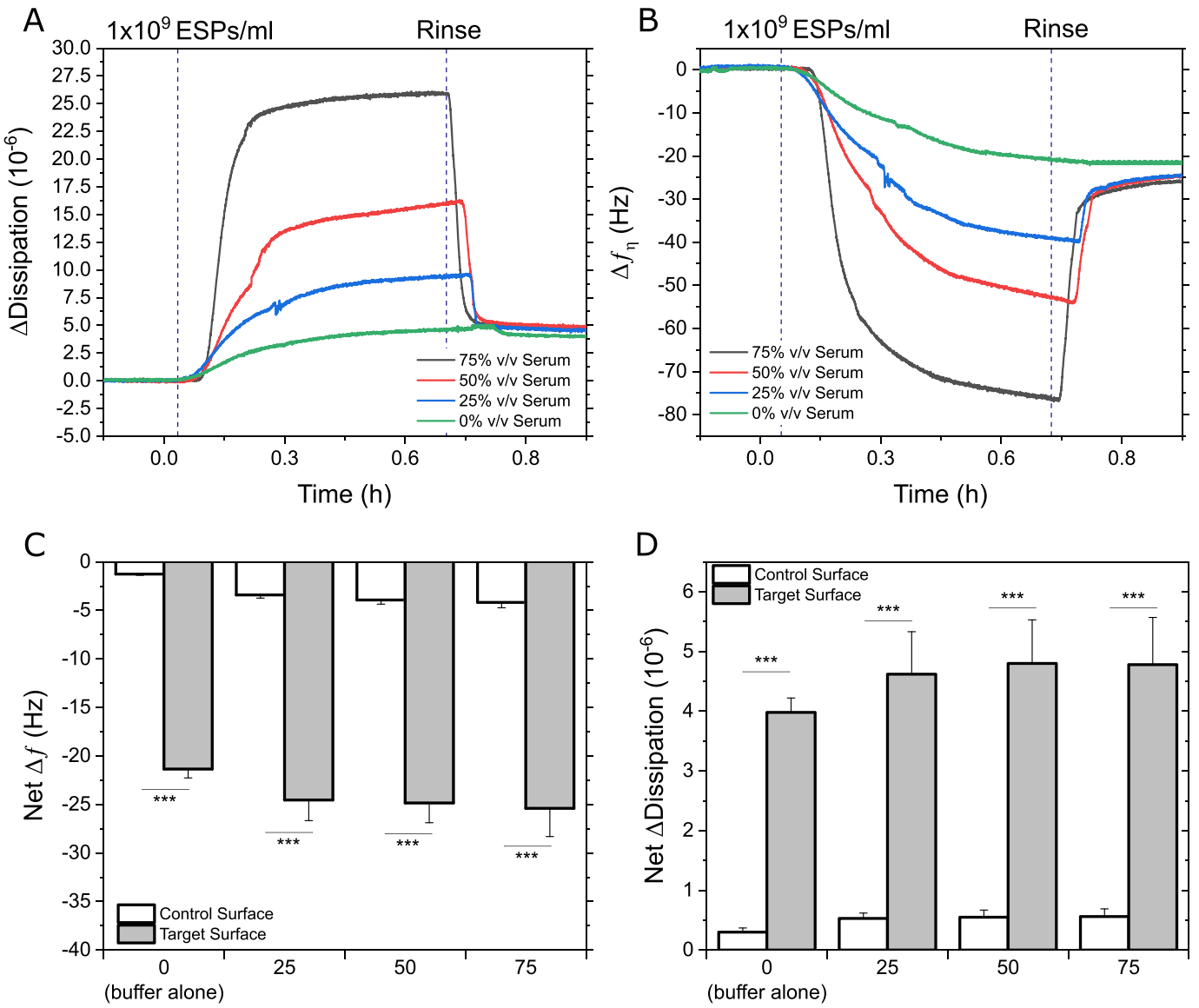

$\mathrm{D}$

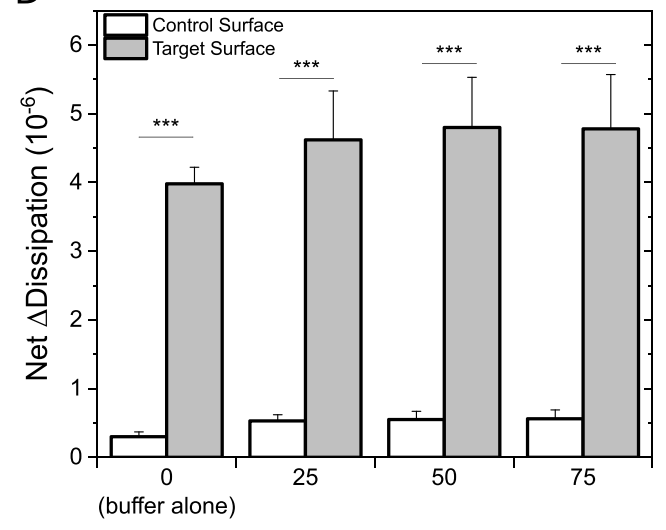

$\%$ Serum in ESP sample

E
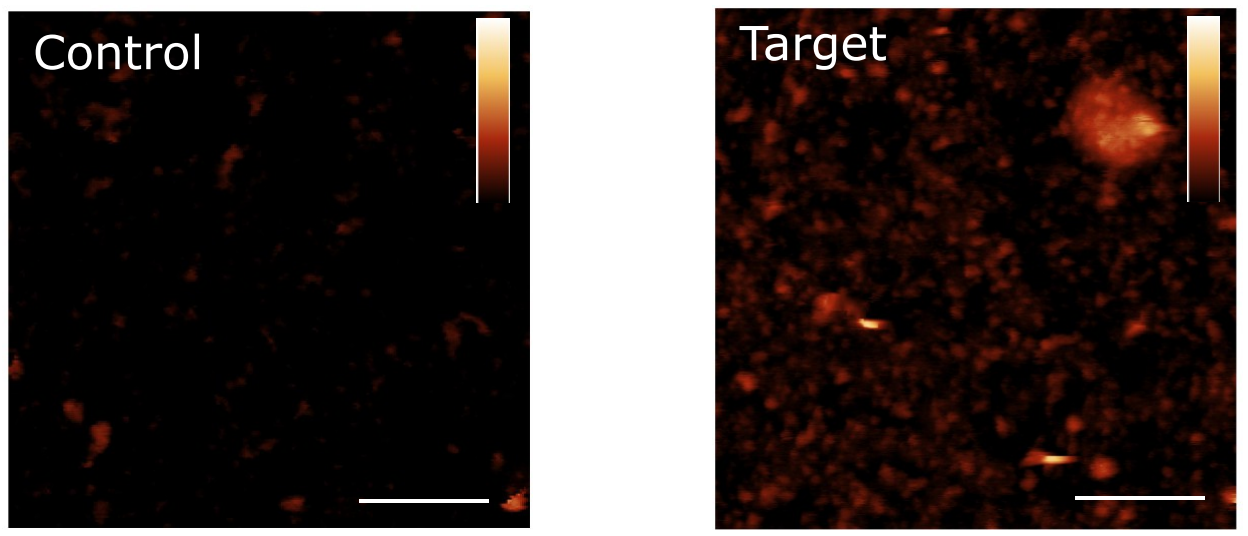

Figure 4. Selectivity of the QCM-D immuno-sensing approach toward CD63-postive exosomes in human serum. (A) Example frequency and (B) dissipation profiles from target surfaces (anti-CD63). (C) Bar chart comparing net frequency change and (D) net dissipation change between target and control surfaces (control-isotype) against $1 \times 10^{9} \mathrm{ESPs} / \mathrm{mL}$ spiked in increasing concentrations of human serum. Average QCM-D data taken from three independent experiments. Student $t$-test (two-tailed) compared responses from the control and target sensor $(* * * p<0.001)$. (E) AFM micrographs comparing control and target surfaces post-ESP incubation in 75\% v/v human serum. Scale bar: $200 \mathrm{~nm}$. Color scale (height): 100 $\mathrm{nm})$.

our view, sensing CD63 protein as part of a vesicular structure provides an amplified and sensitive dissipation response, without the need for a secondary probe.

These QCM-D responses were supported by in-liquid AFM measurements, as particles within the exosome size range were detected (Figure 4E) on the targeted surface, while almost no vesicular material was seen to be bound on the substrate functionalized with control-IgG. Detected particles on the target surface had an average height of $53 \pm 13 \mathrm{~nm}$ (mean \pm standard deviation, $n=15$ particles). To this end, surfaceinduced deformation of exosomes upon adsorption needs to be considered, which likely reduced the observed height from the nominal value. ${ }^{62}$ The average particle diameter was determined to be $64 \pm 9 \mathrm{~nm}$ ( $n=15$ particles, thus suggesting that the majority of exosomes expressing CD63 were smaller than the mean $(93.7 \mathrm{~nm})$ and modal $(86.5 \mathrm{~nm})$ particle size of the ESP sample (Figure 1B), which supports previous findings by Rupert et al. ${ }^{62}$ We note that the observed QCM-D responses 
A

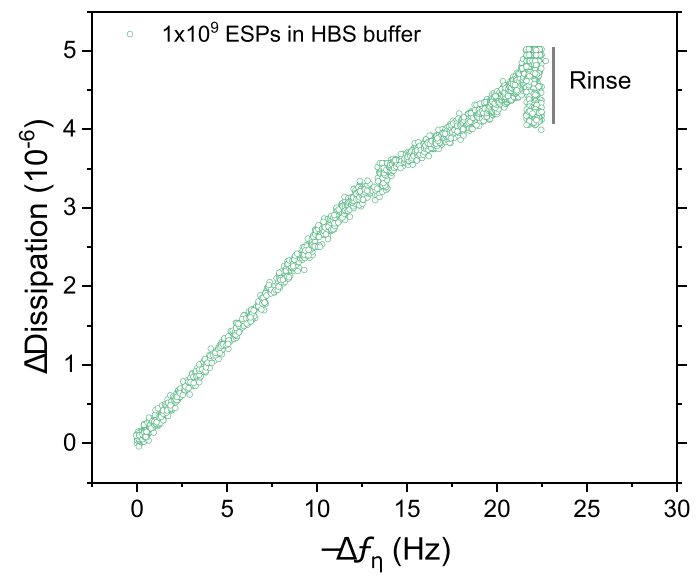

C

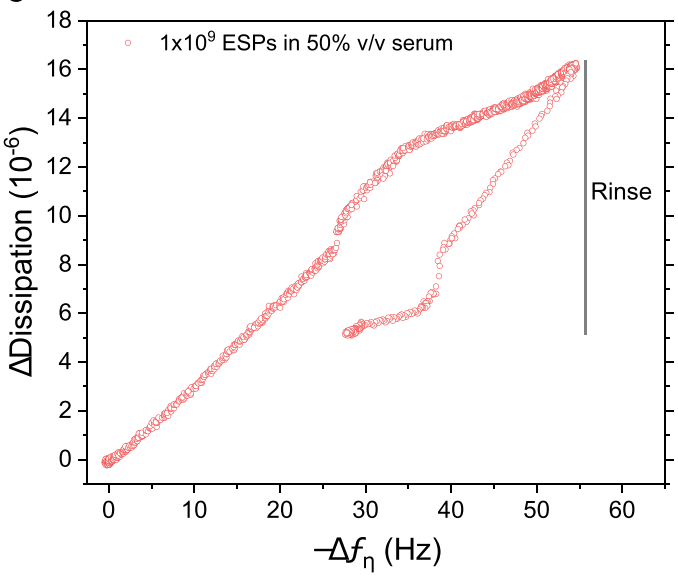

B

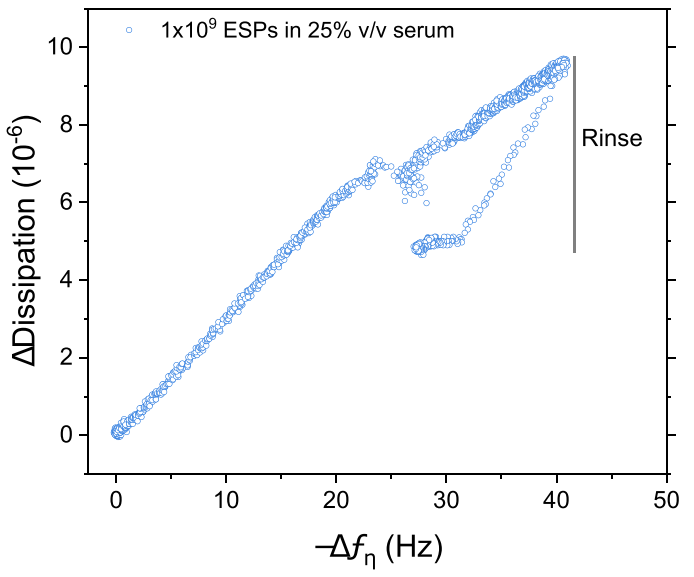

D

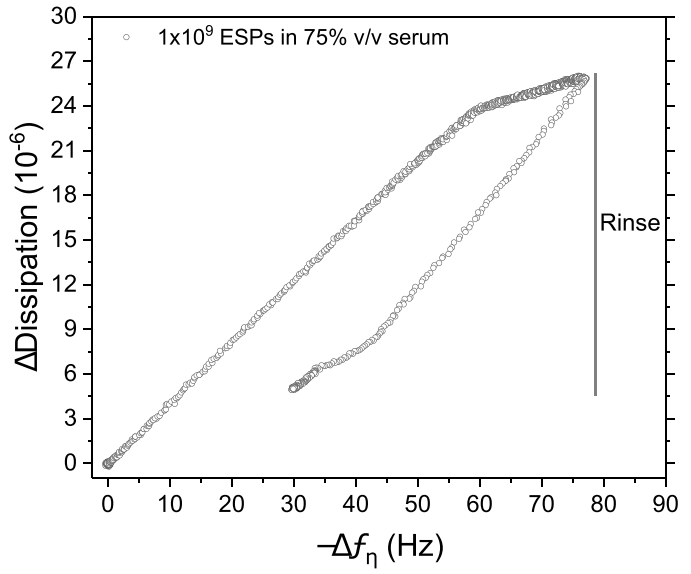

Figure 5. Dissipation change as a function of frequency change for $1 \times 10^{9} \mathrm{ESPs} / \mathrm{mL}$ binding to the target immuno-sensing surface in (A) $0 \% \mathrm{v} / \mathrm{v}$ serum, (B) $25 \% \mathrm{v} / \mathrm{v}$ serum, (C) $50 \% \mathrm{v} / \mathrm{v}$ serum, and (D) $75 \% \mathrm{v} / \mathrm{v}$ serum.

were generally below the expected values for a densely packed adlayer of particles ranging from 50 to $100 \mathrm{~nm} .{ }^{63}$ On the basis of the evidence obtained by AFM, the lower readings are likely attributed to limited sensor coverage by bound exosomes.

The frequency measurement, in particular, highlights a small degree of residual, nonspecific (nonexosomal) binding that occurred on the control surfaces (Figure 4C,D). This indicates that some rigid adsorbates remained, while dissipative, loosely bound particles were removed from the surface with ease. The source of this phenomenon is likely attributed to the complexity of human serum, which is contaminated with its own proteins, lipids, and electrolytes. Fortunately, this phenomenon does not hinder ESP specificity, with high SNRs and differences between target and control responses remaining statistically significant. This is of analytical importance as it ensures the platform sufficiently discriminates between CD63-positive vesicles and other colloidal contaminants. We note the role of the SAM composition for nonspecific protein binding. As shown in Figure S5, we found a greatly decreased propensity for fouling in samples with a mixed PEG-OEG SAM, which is in line with previous studies. ${ }^{64}$

In order to elucidate changes in conformation during the ESP binding process, plots that display the change in dissipation as a function of the change in frequency are shown in Figure 5A-D. Moreover, the reaction fingerprint may be ascertained, i.e., how the viscoelastic properties of the layer changed (approximated by dissipation) with adsorbed mass (approximated by frequency). In all instances, viscoelasticity was found to increase with adsorbed mass, suggesting that both the specific binding of ESPs and nonspecific adsorption of serum contaminants induced significant friction in the sensor adlayer. A rinse of the sensor surface elicited significant concomitant decreases in frequency and dissipation for serum containing samples, consistent with dissipative material being removed from the bound layer (Figure 5C,D). Conversely, no change in frequency was observed alongside the small decrease in dissipation for the ESP in HBS buffer sample, suggesting that any removed material may have not been bound to the sensor surface (thus not affecting mass or layer thickness) while weakly contributing to energy dissipation during oscillatory decay (Figure 5A). Tymchenko et al. previously reported on conformational changes (spreading) of cellular layers, which imparted negative dissipation effects but negligible mass changes, suggesting a similar rearrangement of ESPs during this phase. ${ }^{65}$ Another possibility may lie in the difficulty to interpret the binding of certain viscoelastic microparticles, which elicit both positive and negative effects on oscillatory frequency, a behavior explained by the coupled-resonator model. ${ }^{66}$

Additionally, to verify that the responses were not limited by the binding reaction, the introductory flow rate of a sample was increased from $10 \mu \mathrm{L} / \mathrm{min}$ to $80 \mu \mathrm{L} / \mathrm{min}$ and $120 \mu \mathrm{L} / \mathrm{min}$ 

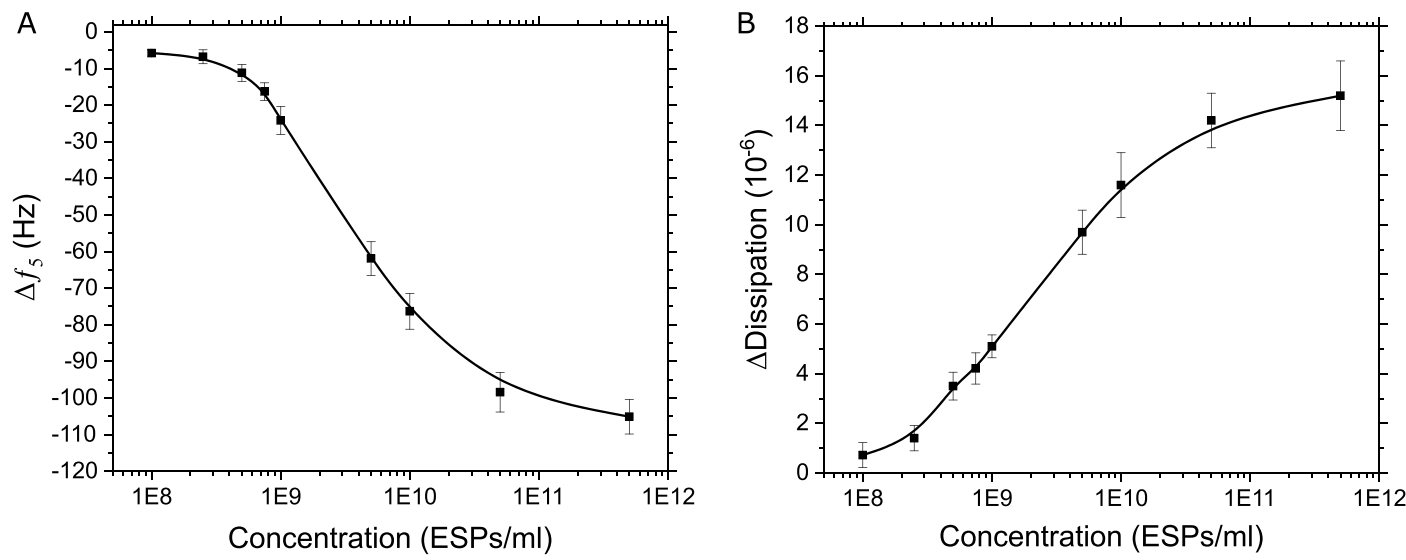

Figure 6. QCM-D immuno-sensor performance against varying concentrations of ESPs spiked in 75\% v/v human serum. (A) Frequency and (B) corresponding dissipation response curves. Standard deviation determined from three independent experiments.

(Figure S6A,B). The increase in adsorption rate was proportional to the cube root of the flow rate, indicating masstransport limited binding (Figure S6C). ${ }^{67}$ These findings are consistent with diffusion of exosomes to the detection antibody being the rate limiting step during the adsorption not the binding kinetics.

Having established the platform's specificity, the sensitivity was initially determined using varying concentrations of SECpurified ESPs in HBS buffer (Figure S3). The same concentrations of EPSs were spiked into $75 \% \mathrm{v} / \mathrm{v}$ serum, revealing marginally elevated LOD and LOQ values as compared to sensing in HBS buffer (Figure 6A,B). Given our findings of a small degree of nonspecific binding from serum matrices (Figure 4), these results are expected and encouraging considering the relatively small increment in LOD and LOQ (Table 2). For both matrices, the dissipation mode

Table 2. QCM-D Immunosensor LOD and LOQ Values

\begin{tabular}{lcccccc} 
& \multicolumn{2}{c}{ LOD $(\mathrm{ESPs} / \mathrm{mL})$} & & \multicolumn{2}{c}{ LOQ $(\mathrm{ESPs} / \mathrm{mL})$} \\
\cline { 2 - 3 } \cline { 5 - 6 } sample media & frequency & dissipation & & frequency & dissipation \\
HBS buffer & $1.7 \times 10^{8}$ & $1.1 \times 10^{8}$ & & $8.2 \times 10^{8}$ & $3.3 \times 10^{8}$ \\
$75 \%$ v/v serum & $2.9 \times 10^{8}$ & $1.4 \times 10^{8}$ & & $9.4 \times 10^{8}$ & $4.5 \times 10^{8}$
\end{tabular}

of measurement showed a higher sensitivity relative to frequency, particularly in $75 \% \mathrm{v} / \mathrm{v}$ serum, outlining its utility in distinguishing CD63-positive exosomes among complex media. These values may be further improved by increasing the saturation capacity of the sensor, allowing for increased capture and coverage of exosomes.

Notably, the sensitivity by QCM-D reported herein is superior to some commercially available immunoassays toward exosomal CD63. ${ }^{68}$ Other recently reported approaches, e.g., interferometric plasmonic imaging of exosomes, ${ }^{69}$ demonstrated similar limits of detection. Some detection platforms have shown superior sensitivity in terms of particle concentration. Ko et al. devised an optofluidic device with sensitivity of up to $1.1 \times 10^{7}$ total particles $/ \mathrm{mL}$. $^{70}$ Zhou et al. combined electrochemistry with an aptamer probe to sense exosomes down to $1 \times 10^{6}$ total particles $/ \mathrm{mL} .^{26}$ Recently, Lim et al. showcased a LOD of just 200 exosomes per milliliter using an amplified plasmonic exosome (APEX) platform. This sensitivity was coupled with the plasmonic shift upon target prefibrillar $\mathrm{A} \beta$ localization to surface bound CD63-positive exosomes, enabling measurement comparison and biomarker subtyping between healthy and Alzheimer's Disease (AD) blood samples. ${ }^{71}$ Our presented QCM-D platform could be used to further investigate this binding phenomenon of $\mathrm{A} \beta$ to surface-captured CD63-positive exosomes, as a complementary sensing technique in the clinical characterization of $\mathrm{AD}$.

The limited sensitivity is a potential disadvantage of the adopted QCM-D immunoassay approach and can be attributed to the entire piezoelectric substrate being used for wave propagation. In contrast, surface acoustic wave (SAW) sensors confine the acoustic wave to a thin surface layer of the substrate and are capable of operating at higher frequencies (50 MHz-GHz), thus offering, in principle, pathways to higher sensitivity. ${ }^{72,73}$ Nevertheless, with native exosome counts in serum reported in the range of $0.8 \times 10^{8}$ to $1 \times 10^{9}$ particles per milliliter, ${ }^{74,75}$ the acoustic immunosensor developed in this work can detect exosomes from serum at clinically relevant concentrations. In some biological matrices, exosome concentrations may only reach values as low as $1 \times 10^{7}$ per milliliter. $^{76,77}$ Further modifications are required to reliably improve the platform sensitivity toward this concentration domain. The process currently consumes $300 \mu \mathrm{L}$ for analysis, slightly more than commercially available ELISAs. Improvements such as reducing the volume of the sample chamber, tubing dead volume, and blocking nonsensing surfaces by preincubation with bovine serum albumin (BSA) may reduce the sample requirement down to $20 \mu \mathrm{L}$, yet above minimal requirements for some SPR and electrochemical setups of less than $5 \mu \mathrm{L} .^{27}$

Importantly, the platform offers a dual mode assessment of exosomes, with dissipation describing the stiffness of the adsorbate relative to the frequency change, lending a superior degree of selectivity to the procedure. This is an advantage over conventional immunoassays, which often deliver a single method of discrimination (e.g., colorimetric or electrochemical immunoassays). Another advantage over a traditional, single end point ELISA sandwich is an ability to make measurements in real time, avoiding lags associated with sample manipulation for signal amplification and indirect assessment.

Beyond serving as a useful quality control tool, the clinical utility of sensing exosomal CD63 has been highlighted by earlier work from Logozzi et al., which demonstrated how CD63-positive exosomes may serve as biomarkers due to their increased abundance in melanoma patients. ${ }^{68}$ More recently, Miki et al. identified exosomal CD63 as a potential prognostic marker in gastric cancer. ${ }^{78}$ QCM-D offers a robust platform to 
analytically supplement these research areas, while being applicable to other exosomal biomarkers.

For QCM-D to be adopted in a clinical diagnostic setting, additional efforts should focus on two areas: (i) advancing the current sensitivity to match plasmonic approaches and (ii) converting QCM-D responses into quantitative information about exosome concentrations. The former is desirable but not a necessity for the adsorption of particles in an exosomal size range, providing that robustness of measurement is displayed. Nonetheless, this can be achieved through devising novel surface functionalization with improved binding capacity and exosome entrapment. The latter is met with challenges of current models such as the Sauerbrey or Voigt methods, which both assume homogeneous layer formation. ${ }^{52}$ The introduction of a formalism to account for the discrete and dissipative nature of exosome binding, along with the coupled solvated mass, would further enhance the analytical insights offered by QCM-D. However, this is a nontrivial task due to multiple measurement parameters, the complexity of sample structure, and the difficulty in distinguishing between coupled water and the bulk solvent. A possible approach is to replace water with $\mathrm{D}_{2} \mathrm{O}$. This would increase the shear viscosity of the bulk liquid while not affecting the kinetic or equilibrium state. Hence, discerned differences in frequency between water and $\mathrm{D}_{2} \mathrm{O}$ would allow one to determine mass contribution by the particle and coupled water fractions, respectively. ${ }^{79}$ Alternatively, combining the QCM-D measurement with optical techniques, such as SPR, has shown advantages to decoupling the contribution from layer hydration, thus offering pathways to identify the proportion of response attributed to the species of interest. $^{80}$

\section{CONCLUSION}

This study establishes a QCM-D transduced immuno-sensing approach as a complementary technique for exosome characterization. Unlike other methods, we exploit a combination of mass, viscoelasticity, and surface antigens of exosomes. This allows sensitive and selective detection of CD63-positive exosomes in $75 \% \mathrm{v} / \mathrm{v}$ human serum without the need of a secondary label. At concentrations of $1 \times 10^{9}$ ESPs/ $\mathrm{mL}$, we achieved signal-to-noise ratios of 5.8 and 11.4 compared to a control surface for frequency and dissipation measurements, respectively. With a detection limit as low as $1.4 \times 10^{8} \mathrm{ESPs} / \mathrm{mL}$, acoustic biosensing presents a direct route to phenotypically subtype exosomes at native concentrations, thus offering advantages in fundamental bioanalytical characterization with a potential to integrate with real-time liquid biopsies for clinical diagnostics in the future.

\section{ASSOCIATED CONTENT}

\section{(5) Supporting Information}

The Supporting Information is available free of charge at https://pubs.acs.org/doi/10.1021/acs.analchem.9b05736.

Cell-culture; microBCA protein assay; Western blot; SEC fraction particle purity; overnight in situ formation of SAM; QCM-D immunosensor performance toward CD63-positive ESPs in HBS buffer; QCM-D immunosensor specificity toward CD63-positive ESPs in HBS buffer; antifouling properties of sensor monolayers; demonstration of diffusion limited conditions for exosome sensing (PDF)

\section{AUTHOR INFORMATION}

\section{Corresponding Author}

Stefan Guldin - Department of Chemical Engineering, University College London, London WC1E 7JE, United Kingdom; ๑ orcid.org/0000-0002-4413-5527; Email: s.guldin@ucl.ac.uk

\section{Authors}

Jugal Suthar - UCL School of Pharmacy and Department of Chemical Engineering, University College London, London WC1N 1AX, United Kingdom

Edward S. Parsons - London Centre for Nanotechnology, London WC1H OAH, United Kingdom

Bart W. Hoogenboom - London Centre for Nanotechnology, London WC1H OAH, United Kingdom; Department of Physics and Astronomy, University College London, London WC1E 6BT, United Kingdom; 10 orcid.org/0000-0002-8882-4324

Gareth R. Williams - UCL School of Pharmacy, University College London, London WC1N 1AX, United Kingdom; (1) orcid.org/0000-0002-3066-2860

Complete contact information is available at:

https://pubs.acs.org/10.1021/acs.analchem.9b05736

\section{Notes}

The authors declare no competing financial interest.

\section{ACKNOWLEDGMENTS}

The authors thank the Engineering and Physical Sciences Research Council (EPSRC; EP/L01646X), the Medical Research Council (MRC, MR/R000328/1), University College London, and University of Nottingham CDT in Advanced Therapeutics and Nanomedicines for financial support. The authors also thank Dr. Benjamin Weil and Prof. Mark Lowdell from the Centre for Cell, Gene, and Tissue Therapeutics at the Royal Free London NHS Foundation Trust, for donating the HUMSCCM used in this research.

\section{REFERENCES}

(1) Théry, C.; Boussac, M.; Véron, P.; Ricciardi-Castagnoli, P.; Raposo, G.; Garin, J.; Amigorena, S. J. Immunol. 2001, 166, 73097318.

(2) Aguilera-Rojas, M.; Badewien-Rentzsch, B.; Plendl, J.; Kohn, B.; Einspanier, R. BMC Vet. Res. 2018, 14, 179.

(3) Van Niel, G.; Mallegol, J.; Bevilacqua, C.; Candalh, C.; Brugiere, S.; Tomaskovic-Crook, E.; Heath, J. K.; Cerf-Bensussan, N.; Heyman, M. Gut 2003, 52, 1690-1697.

(4) Kowal, J.; Arras, G.; Colombo, M.; Jouve, M.; Morath, J. P.; Primdal-Bengtson, B.; Dingli, F.; Loew, D.; Tkach, M.; Théry, C. Proc. Natl. Acad. Sci. U. S. A. 2016, 113, E968-E977.

(5) Colombo, M.; Raposo, G.; Théry, C. Annu. Rev. Cell Dev. Biol. 2014, 30, 255-289.

(6) Coleman, B. M.; Hill, A. F. Semin. Cell Dev. Biol. 2015, 40, 8996.

(7) Ibrahim, A. G. E.; Cheng, K.; Marbàn, E. Stem Cell Rep. 2014, 2, 606-619.

(8) Saman, S.; Kim, W. H.; Raya, M.; Visnick, Y.; Miro, S.; Saman, S.; Jackson, B.; McKee, A. C.; Alvarez, V. E.; Lee, N. C.; Hall, G. F. J. Biol. Chem. 2012, 287, 3842-3849.

(9) Gauthier, S. A.; Perez-Gonzalez, R.; Sharma, A.; Huang, F.-K.; Alldred, M. J.; Pawlik, M.; Kaur, G.; Ginsberg, S. D.; Neubert, T. A.; Levy, E. Acta Neuropathol. Commun. 2017, 5, 65.

(10) Taylor, D. D.; Gercel-Taylor, C. Philos. Trans. R. Soc., B 2014, $369,165-171$. 
(11) Lin, S. Y.; Chang, C. H.; Wu, H. C.; Lin, C. C.; Chang, K. P.; Yang, C. R.; Huang, C. P.; Hsu, W. H.; Chang, C. T.; Chen, C. J. Sci. Rep. 2016, 6, 34446 DOI: 10.1038/srep34446.

(12) Gardiner, C.; Ferreira, Y. J.; Dragovic, R. A.; Redman, C. W.; Sargent, I. L. J. Extracell. Vesicles 2013, 2, 19671.

(13) Vogel, R.; et al. J. Extracell. Vesicles 2016, 5, 31242.

(14) Bradford, M. M. Anal. Biochem. 1976, 72, 248-254.

(15) Lobb, R. J.; Becker, M.; Wen Wen, S.; Wong, C. S. F.; Wiegmans, A. P.; Leimgruber, A.; Moller, A. J. Extracell. Vesicles 2015, 4, 27031.

(16) Abramowicz, A.; Widlak, P.; Pietrowska, M. Mol. BioSyst. 2016, 12, 1407-1419.

(17) Erdbrügger, U.; Lannigan, J. Cytometry, Part A 2016, 89, 123134.

(18) Lannigan, J.; Erdbruegger, U. Methods 2017, 112, 55-67.

(19) Lee, S.; Zhu, X.; Sha, Q. Neuroacanthocytosis Syndr. II 2008, 7, 107-114.

(20) Ferguson, S. W.; Nguyen, J. J. Controlled Release 2016, 228, 179-190.

(21) Ren, R.; Cai, G.; Yu, Z.; Zeng, Y.; Tang, D. Anal. Chem. 2018, 90, 11099-11105.

(22) Luo, Z.; Zhang, L.; Zeng, R.; Su, L.; Tang, D. Anal. Chem. 2018, 90, 9568-9575.

(23) He, M.; Crow, J.; Roth, M.; Zeng, Y.; Godwin, A. K. Lab Chip 2014, 14, 3773-3780.

(24) Wang, Y.; Yuan, W.; Kimber, M.; Lu, M.; Dong, L. ACS Sensors 2018, 3, 1616-1621.

(25) Daaboul, G. G.; Gagni, P.; Benussi, L.; Bettotti, P.; Ciani, M.; Cretich, M.; Freedman, D. S.; Ghidoni, R.; Ozkumur, A. Y.; Piotto, C.; Prosperi, D.; Santini, B.; Ünlü, M. S.; Chiari, M. Sci. Rep. 2016, 6, 37246.

(26) Zhou, Q.; Rahimian, A.; Son, K.; Shin, D. S.; Patel, T.; Revzin, A. Methods 2016, 97, 88-93.

(27) Doldán, X.; Fagúndez, P.; Cayota, A.; Lá1z, J.; Tosar, J. P. Anal. Chem. 2016, 88, 10466-10473.

(28) Im, H.; Shao, H.; Park, Y. I.; Peterson, V. M.; Castro, C. M.; Weissleder, R.; Lee, H. Nat. Biotechnol. 2014, 32, 490-495.

(29) Raghu, D.; Christodoulides, J. A.; Christophersen, M.; Liu, J. L.; Anderson, G. P.; Robitaille, M.; Byers, J. M.; Raphael, M. P. PLoS One 2018, 13, e0202773.

(30) Rupert, D. L.; Lässer, C.; Eldh, M.; Block, S.; Zhdanov, V. P.; Lotvall, J. O.; Bally, M.; Höök, F. Anal. Chem. 2014, 86, 5929-5936.

(31) Helmerhorst, E.; Chandler, D. J.; Nussio, M.; Mamotte, C. D. Clin. Biochem. 2012, 33, 161-173.

(32) Nguyen, H. H.; Park, J.; Kang, S.; Kim, M. Sensors 2015, 15, 10481-10510.

(33) Qiu, Z.; Shu, J.; Liu, J.; Tang, D. Anal. Chem. 2019, 91, 12601268.

(34) Yu, Z.; Tang, Y.; Cai, G.; Ren, R.; Tang, D. Anal. Chem. 2019, 91, 1222-1226.

(35) Hook, F.; Rodahl, M.; Keller, C.; Glasmastar, K.; Fredriksson, C.; Dahiqvist, P.; Kasemo, B. Proc. Annu. IEEE Int. Freq. Control Symp. 1999, 2, 966-972.

(36) Li, X.; Song, S.; Shuai, Q.; Pei, Y.; Aastrup, T.; Pei, Y.; Pei, Z. Sci. Rep. 2015, 5, 14066.

(37) Tao, W.; Xie, Q.; Wang, H.; Ke, S.; Lin, P.; Zeng, X. Sensors 2015, 15, 25746-25760.

(38) Johannsmann, D.; Reviakine, I.; Richter, R. P. Anal. Chem. 2009, 81, 8167-8176.

(39) Uludag, Y.; Tothill, I. E. Talanta 2010, 82, 277-282.

(40) Pirincci, S. S.; Ertekin, O.; Laguna, D. E.; Ozen, F. S.; Ozturk,

Z. Z.; Ozturk, S. Sensors 2018, 18, 1161.

(41) Tang, D.; Zhang, B.; Tang, J.; Hou, L.; Chen, G. Anal. Chem. 2013, 85, 6958-6966.

(42) Böing, A. N.; van der Pol, E.; Grootemaat, A. E.; Coumans, F. A.; Sturk, A.; Nieuwland, R. J. Extracell. Vesicles 2014, 3, 23430.

(43) Ayela, C.; Roquet, F.; Valera, L.; Granier, C.; Nicu, L.; Pugnìere, M. Biosens. Bioelectron. 2007, 22, 3113-3119.
(44) Kim, Y. H.; Kim, J. P.; Han, S. J.; Sim, S. J. Sens. Actuators, B 2009, 139, 471-475.

(45) Knoll, W.; Liley, M.; Piscevic, D.; Spinke, J.; Tarlov, M. J. Adv. Biophys. 1997, 34, 231-251.

(46) Shrivastava, A.; Gupta, V. Chronicles Young Sci. 2011, 2, 21.

(47) Gámez-Valero, A.; Monguió-Tortajada, M.; Carreras-Planella, L.; Franquesa, M.; Beyer, K.; Borràs, F. E. Sci. Rep. 2016, 6, 33641.

(48) Welton, J. L.; Webber, J. P.; Botos, L. A.; Jones, M.; Clayton, A. J. Extracell. Vesicles 2015, 4, 27269.

(49) Vashist, S. K. Diagnostics 2012, 2, 23-33.

(50) Wilchek, M.; Bayer, E. A. Biomol. Eng. 1999, 16, 1-4.

(51) Dubacheva, G. V.; Araya-Callis, C.; Geert Volbeda, A.; Fairhead, M.; Codee, J.; Howarth, M.; Richter, R. P. J. Am. Chem. Soc. 2017, 139, 4157-4167.

(52) Reviakine, I.; Johannsmann, D.; Richter, R. P. Anal. Chem. 2011, 83, 8838-8848.

(53) Tan, Y. H.; Liu, M.; Nolting, B.; Go, J. G.; Gervay-Hague, J.; Liu, G. Y. ACS Nano 2008, 2, 2374-2384.

(54) Baniukevic, J.; Kirlyte, J.; Ramanavicius, A.; Ramanaviciene, A. Sens. Actuators, B 2013, 189, 217-223.

(55) Kausaite-Minkstimiene, A.; Ramanaviciene, A.; Kirlyte, J.; Ramanavicius, A. Anal. Chem. 2010, 82, 6401-6408.

(56) Trilling, A. K.; Harmsen, M. M.; Ruigrok, V. J.; Zuilhof, H.; Beekwilder, J. Biosens. Bioelectron. 2013, 40, 219-226.

(57) Balevicius, Z.; Ramanaviciene, A.; Baleviciute, I.; Makaraviciute, A.; Mikoliunaite, L.; Ramanavicius, A. Sens. Actuators, B 2011, 160, $555-562$.

(58) Hwang, S. S.; Chan, H.; Sorci, M.; Van Deventer, J.; Wittrup, D.; Belfort, G.; Walt, D. Anal. Biochem. 2019, 566, 40-45.

(59) Chen, Q.; Tang, W.; Wang, D.; Wu, X.; Li, N.; Liu, F. Biosens. Bioelectron. 2010, 26, 575-579.

(60) Grieshaber, D.; De Lange, V.; Hirt, T.; Lu, Z.; Vörös, J. Sensors 2008, 8, 7894-7903.

(61) Jackman, J. A.; Yorulmaz Avsar, S.; Ferhan, A. R.; Li, D.; Park, J. H.; Zhdanov, V. P.; Cho, N.-J. Anal. Chem. 2017, 89, 1102-1109.

(62) Rupert, D. L. M.; Shelke, G. V.; Emilsson, G.; Claudio, V.; Block, S.; Lasser, C.; Dahlin, A.; Lotvall, J. O.; Bally, M.; Zhdanov, V. P.; Hook, F. Anal. Chem. 2016, 88, 9980-9988.

(63) Morita, S.; Nukui, M.; Kuboi, R. J. Colloid Interface Sci. 2006, 298, 672-678.

(64) Lokanathan, A. R.; Zhang, S.; Regina, V. R.; Cole, M. A.; Ogaki, R.; Dong, M.; Besen- bacher, F.; Meyer, R. L.; Kingshott, P. Biointerphases 2011, 6, 180-188.

(65) Tymchenko, N.; Nileback, E.; Voinova, M. V.; Gold, J.; Kasemo, B.; Svedhem, S. Biointerphases 2012, 7, 43.

(66) Tarnapolsky, A.; Freger, V. Anal. Chem. 2018, 90, 1396013968.

(67) Van Der Meulen, S. A.; Dubacheva, G. V.; Dogterom, M.; Richter, R. P.; Leunissen, M. E. Langmuir 2014, 30, 6525-6533.

(68) Logozzi, M.; De Milito, A.; Lugini, L.; Borghi, M.; Calabro, L.; Spada, M.; Perdicchio, M.; Marino, M. L.; Federici, C.; Iessi, E.; Brambilla, D.; Venturi, G.; Lozupone, F.; Santinami, M.; Huber, V.; Maio, M.; Rivoltini, L.; Fais, S. PLoS One 2009, 4, e5219.

(69) Zeng, X.; Yang, Y.; Zhang, N.; Ji, D.; Gu, X.; Jornet, J. M.; Wu, Y.; Gan, Q. IEEE J. Sel. Top. Quantum Electron. 2019, 25, 25.

(70) Ko, J.; Hemphill, M. A.; Gabrieli, D.; Wu, L.; Yelleswarapu, V.; Lawrence, G.; Pennycooke, W.; Singh, A.; Meaney, D. F.; Issadore, D. Sci. Rep. 2016, 6, 31215.

(71) Lim, J.; Choi, M.; Lee, H.; Kim, Y. H.; Han, J. Y.; Lee, E. S.; Cho, Y. J. Nanobiotechnol. 2019, 17, 1.

(72) Kankare, J. Langmuir 2002, 18, 7092-7094.

(73) Xu, Z.; Yuan, Y. J. RSC Adv. 2019, 9, 8411-8414.

(74) De Vrij, J.; Maas, S. L.; Van Nispen, M.; Sena-Esteves, M.; Limpens, R. W.; Koster, A. J.; Leenstra, S.; Lamfers, M. L.; Broekman, M. L. Nanomedicine 2013, 8, 1443-1458.

(75) Huang, X.; Yuan, T.; Tschannen, M.; Sun, Z.; Jacob, H.; Du, M.; Liang, M.; Dittmar, R. L.; Liu, Y.; Liang, M.; Kohli, M.; Thibodeau, S. N.; Boardman, L.; Wang, L. BMC Genomics 2013, 14, 319 DOI: $10.1186 / 1471-2164-14-319$. 
(76) Wongkaew, N. Anal. Bioanal. Chem. 2019, 411, 4251-4264.

(77) Soares Martins, T.; Catita, J.; Martins Rosa, I.; A. B. da Cruz e Silva, O.; Henriques, A. G. PLoS One 2018, 13, e0198820.

(78) Miki, Y.; Yashiro, M.; Okuno, T.; Kuroda, K.; Togano, S.; Hirakawa, K.; Ohira, M. PLoS One 2018, 13, e0202956.

(79) Craig, V. S.; Plunkett, M. J. Colloid Interface Sci. 2003, 262, 126-129.

(80) Höök, F.; Kasemo, B.; Nylander, T.; Fant, C.; Sott, K.; Elwing, H. Anal. Chem. 2001, 73, 5796-5804. 